\title{
Collaborative Examination Paper Discussion Platform
}

\author{
Madhavi Mihirani ${ }^{1}$, Isuru Dilshan ${ }^{1}$, Dulanga Rajapaksha ${ }^{1}$, Samila Ishara ${ }^{1}$, Pradeep Sanjeewa ${ }^{1}$ \\ K.A. Dilini T. Kulawansa ${ }^{2}$, Thishantha Thilakarathne ${ }^{3}$ \\ Faculty of Information Technology, University of Moratuwa, Sri Lanka \\ Virtusa Polaris Pvt. Ltd, 752 Dr. Danister De Silva Mawatha, Colombo 00900, Sri Lanka
}

\begin{abstract}
Knowledge gathering using discussion, is the best efficient way among the students. In present most of the students rely on internet for gathering information while the main problem of current search features is university students are unable to answer the questions and discuss the past examination papers by using uploaded pdf file. The research has been conducted to develop a software solution to overcome above existing problem. Consequently, collaborative examination paper discussion platform was designed. This solution includes five main modules namely, Administration Module, Data Analytical Module, User Profile Management Module, Document Handling Module and Discussion Forum. Administration module which covers fundamental functionalities related to administrative purpose. Data Analytical analyses the data that are collected from the discussion forum while it helps for system admin to find out on going learning patterns. User Profile Management module consists of registration unit, logging unit, profile display unit and profile edit unit that are given user to capability of maintaining their own profiles. Document handling module has file uploading unit and tagging unit while Discussion forum provides an area for user to add comments, answers, and images. When considering about the overall system, there are three types of users, student, lecturers and administrators. Inputs of the system are Examination papers in PDF, Images, Documents, User details, answers, and comments. Outputs in our approach are related answers and comments for questions. PDF file convert into images, retrieve data from database, output related answers are considered as process. The overall system has been developed to run on Windows. The proposed system has some special features which are not available in other existing systems such as answering questions using pdf and uploading pdf file. The system was evaluated, using questionnaire and module testing.
\end{abstract}

Keywords - collaborative, Examination papers, pdf files, modules, students.

\section{Introduction}

In present, different kind of social networking sites are used by many people for information seeking and solving their problems. As a result, social questioning and answering web platform were designed
(LinuxQustions, Yahoo, StackOverfolw, etc.). Today students are commonly used questions and answers web platforms to seek information through the internet. It helps to better search experiences or over conventional information retrieval methods as well as providing more personalized answers. When we consider about university studies, already we are using collaboratively learning web platform such as Moodle. However, the main problem of current search features are students cannot collect answers or any related information to improve their knowledge by using this web application. Because those web platforms help users to get only pdf representation of educational materials such as past papers. Therefore, students must have to find proper way for answering questions. In generally number of students gather information as a group. Through the method some problems are raised as a smaller number of students can participate discussions, users cannot learn or study papers by them salves, choose difficult methods for solving problems and not every student can participate for discussion at the same time. To address this issue, we propose a web base application that every and each student can participate with questions-answering process. This application provides an interactive interface for users. So, then users can upload past papers as pdf files, then the system will convert this pdf files into image representation. Then students can select some question on papers by highlighting them and ask better way to solve it or some question related to that highlighted area. Deference between existing learning platform and proposed learning web platform is more user friendly as well as more flexible. 
Proc. of the Eighth Intl. Conf. on Advances in Computing, Electronics and Communication - ACEC 2019

Copyright $\odot$ Institute of Research Engineers and Doctors. All rights reserved.

ISBN: 978-1-63248-165-8 DOI : 10.15224/978-1-63248-165-8-02

Table 1: Comparison between existing Software

\begin{tabular}{|c|c|c|c|c|c|}
\hline $\begin{array}{l}\text { Similar } \\
\text { Applications } \\
\text { Characteristics }\end{array}$ & $\begin{array}{l}\text { Wen } \\
\text { wo }\end{array}$ & $\begin{array}{c}\text { Yaho } \\
\text { o! }\end{array}$ & $\begin{array}{l}\text { Stack } \\
\text { Overfl }\end{array}$ & Quora & $\begin{array}{l}\text { Answ } \\
\text { ers.co }\end{array}$ \\
\hline $\begin{array}{l}\text { 1.Register to the } \\
\text { system }\end{array}$ & $\checkmark$ & $\checkmark$ & $\checkmark$ & $\checkmark$ & $\checkmark$ \\
\hline 2.Ask questions & $\checkmark$ & $\checkmark$ & $\checkmark$ & $\checkmark$ & $\checkmark$ \\
\hline $\begin{array}{l}\text { 3.View question's } \\
\text { answers }\end{array}$ & $\sqrt{ }$ & $\sqrt{ }$ & $\checkmark$ & $\checkmark$ & $\checkmark$ \\
\hline $\begin{array}{l}\text { 4.Rate questions, } \\
\text { answers }\end{array}$ & $x$ & $\checkmark$ & $\checkmark$ & $x$ & $x$ \\
\hline 5.Tag questions & $x$ & $\checkmark$ & $\checkmark$ & $\checkmark$ & $\checkmark$ \\
\hline $\begin{array}{l}\text { 6.Update question } \\
\text { and answers }\end{array}$ & $\checkmark$ & $\checkmark$ & $\checkmark$ & $\checkmark$ & $\checkmark$ \\
\hline $\begin{array}{l}\text { 7.Maintain user } \\
\text { profile }\end{array}$ & $\checkmark$ & $\checkmark$ & $\checkmark$ & $\checkmark$ & $\checkmark$ \\
\hline $\begin{array}{l}\text { 8.Users can earn } \\
\text { popularity }\end{array}$ & $x$ & $\checkmark$ & $\checkmark$ & $x$ & $x$ \\
\hline $\begin{array}{l}\text { 9.Answer question } \\
\text { using pdf file }\end{array}$ & $x$ & $x$ & $x$ & $x$ & $x$ \\
\hline 10.Upload pdf file & $x$ & $x$ & $x$ & $x$ & $x$ \\
\hline
\end{tabular}

Systems

\section{Related work}

In present popular collaborative modes such as Yahoo! Answers, Quora, Stack Overflow, Quora and Answers.com have been extended over the world as quick information seeking methods. Through these applications have focused on usage of quantitative method to analyze the real-world questions and answers as well as academic data. For examples, there are three connection networks in Quora, connecting user and topic through graph, a social graph is used to connect users, and related questions are connected via graph [9].

In Wenwo, questions are directly posted to the site or individuals can post their questions on Weibo [4], Stack Overflow is a question and answer platform for professional and program developers. Community Question Answering (CQA) services contain large archives of previously asked questions and their answers [3] etc. By considering all these things, we recognized the inability of university students to answer their past examination papers by using above mentioned applications. By addressing these problems, we intend to create a collaborative examination paper discussion platform for students who want to do past papers with very correct and exact answer.

\section{Technology adapted}

For developing an examination paper discussion platform, we have to implement a set of activities such as uploading past papers in pdf manner, converting pdf files into images, selecting a particular area on image, providing comments for mentioned questions, rating answers and maintaining the database. Therefore, we need to use applicable technologies for each activity to accomplish our task. When selecting technologies, we considered about server-side scripting, client-side scripting, program libraries, web application frameworks, usability, cost effectiveness etc. considering all these things we selected following technologies to build our examination paper discussion platform. They are Apache, PHP, My SQL, HTML, CSS, JavaScript, Bootstrap.

\section{Modular Approach to the Paper Discussion Platform}

We were able to accomplish our aim \& objectives through this module implementation. We developed our system under five main modules. They are Administration Module, Data Analytical Module, User Profile Management Module, Document Handling Module, and Discussion Forum. These modules were integrated for getting output of complete system.

\section{A. Administration Module}

Administration Module provide fundamental functionalities regarding to administrative purposes. If there are any unauthorized things happen in the system Administrator directly involve the problem through administration module. There are many other functionalities done by this module. This module has dashboard. By using dashboard can show information about users. Tags of all questions their given comments, answers, ranks can show on the dashboard.

\section{B. Data Analytical Module}


This module is regarding making statistics using data that in discussion forum. It helps for find out on going learning patterns of users. In hear we use collected data from data base to analyses current situation of the web site. This Module provide details about how many questions that have been asked, how many answers that have been given to questions, how many questions that haven' $t$ provided answers. And also, it provides how many comments on the system, how many active users currently available, who are the users that frequently use our sites.

\section{User Profile Management Module}

The user has the capability of maintaining their own profiles in this module. User profile management module has many functional units. Namely Registration unit, Logging unit, Profile Display unit, Profile Edit unit.

\section{a. Registration Unit}

Student can register to the system and also Lectures can register through the administrator by using this unit. In this unit student detail such as Password, name and email.

\section{b. Logging Unit}

To logging to the system user can input email as the user name and password that given in the registration unit. If users not online and first they come to logging to the unit, they can see LOGGING command in the screen.

\section{c. Profile Display Unit}

In this unit user can view his profile.

\section{d. Profile Editing Unit}

In this unit user can edit his profile.

\section{Document Handling Module}

This module is used to add pdf files, images, document files, zip file etc. In a pdf file User can select the area that user needs to know on those added material. All the files will be saved in to the server and also details about the files and its name will be store in a MYSQL database.

\section{a. Files Uploading Unit}

When user upload Pdf files, image files etc. those files will be store in inside of APACHE Server folder, and also all the necessary detail about the files will be store MYSQL database.

b. Tagging Unit
In this section pdf file will tag by user on his purpose by specify coordinates. These coordinates also store in database.

\section{E. Discussion Forum}

Discussion forum provides an area for users to add comments, answers, questions, images and codes. As well as discussion forum give a chance for users to reply for others comment.

\section{a. Answering Unit}

According to ask question detail will be get from MYSQL database and show it on the area and when a user provide an answer that answer will store in MYSQL database. Edit answers also Store in database

b. Commenting unit

According to ask question detail will be get from MYSQL database and show it on the area and when a user provide an answer that answer will store in MYSQL database. Edit comments also store in database.

\section{c. Popup unit}

When we click some area that is tagged by user will pop up with that document and its answers and comments etc.

\section{V.Methodologies}

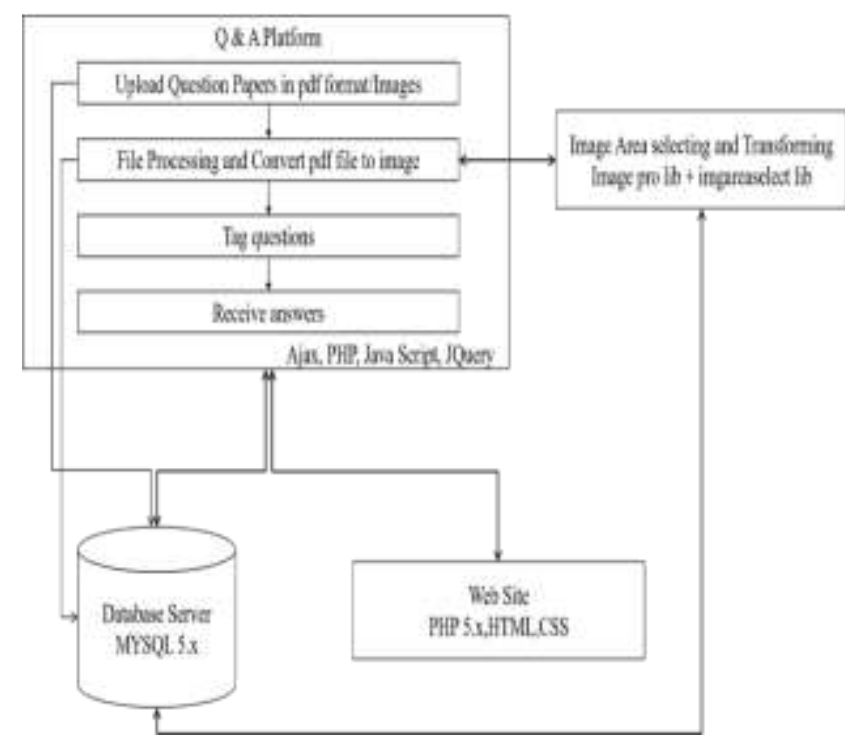

Figure 1: Top Level Architecture of Proposed System 


\section{a. Uploading question papers in pdf format}

Lecturers and students can upload the examination papers into the system as pdf file. And also, users can upload image type documents into system.

\section{b. Convert pdf file to image}

After uploading pdf document, system will convert it into image file which user can handle easier.

\section{c. Tag questions}

By using image file users are capable of selecting a particular area that includes questions what they need to solve, on image.

\section{d. Receive answers}

According to tagged question, system is capable of providing stored answers, which are related to question. Therefore, users can gather rated answers, or they have to wait for suitable answers. In here, other users can provide answers to those questions and rate answers.

\section{e. Image processing}

In above process image and pdf files will not be saved in database. They just save in local folder inside of apache saver. All these things including image tagging, answering for tagged questions, commenting is processed associated with image pro library and image select area library.

\section{f. Database}

Details about all registered students and lecturers, coordinates of selected locations on image, answers that were provided by users are stored in database.

\section{Implementation of our Proposed System}

The proposed system has five different modules and the MYSQL database. Before getting started to develop the system we identified what are the technological interactions between those modules. According to that information gathered we started to develop the system. We used Laravel frame work as our PHP framework for doing implementations of backend. For the implementations of frontend used Bootstrap, CSS, Java script and HTML. All five modules and database were developed using parallel procedures. In user profile management module, we implemented registration part and logging part. Then actor vice we have implemented profile display unit and profile edit unit. In Discussion forum we developed commenting unit and answering unit using same technology. Using jQuery and JavaScript we developed popup unit which is important to view answers and comments on tagged questions. File upload module implementations was directly connecting with the MYSQL database. If the database integration was started early main part of it was developed parallel to this module. Administration module was developed using Bootstrap, CSS and MYSQL. Data Analytical module was implemented at the latter part of the project, because the necessary data to development of this module directly related with other modules. All five modules and database were integrated correctly while testing of each module step by step. Here we included the flow chart to get on overall idea about our proposed system.

\section{Evaluation}

We developed the system with the aim of achieving drawbacks of existing systems. Specially the characteristics such as uploading pdf file and answering questions using pdf file are not available in the existing systems while our developed systems has been included all those characteristics. In here we evaluated our system through the questionnaire which helps to determine the expected functional and non-functional requirements of undergraduate students have been met. Evaluation process was done under seven different aspects which can be used to measure user satisfaction level [30]. We developed a questionnaire for system users such as undergraduate students and lecturers who were registered in system, to measure the satisfaction level of users, regarding examination paper discussion platform as well as to measure the user-friendliness of the application and to measure the usefulness of the application. And also, modular testing was done for evaluating system technically. 
Proc. of the Eighth Intl. Conf. on Advances in Computing, Electronics and Communication - ACEC 2019

Copyright $\odot$ Institute of Research Engineers and Doctors. All rights reserved.

ISBN: 978-1-63248-165-8 DOI : 10.15224/978-1-63248-165-8-02

Table 2: user feedback analysis

\begin{tabular}{|c|c|c|c|c|c|c|c|c|c|}
\hline & & \multicolumn{5}{|c|}{ Rating } & & & \\
\hline & & $\begin{array}{l}\text { Very } \\
\text { Good }\end{array}$ & Good & Satisfactary & Poor & $\begin{array}{l}\text { Very } \\
\text { Poor }\end{array}$ & & & \\
\hline Na. & Evaluation Aspect & 5 & 4 & 3 & 2 & 1 & $\begin{array}{l}\text { Total } \\
\text { Scare }\end{array}$ & $\begin{array}{l}\text { No. of } \\
\text { eesponse }\end{array}$ & Raties \\
\hline & $\begin{array}{l}\text { User friendliness of } \\
\text { the applicatioe }\end{array}$ & 39 & 9 & 1 & 1 & 0 & 236 & 50 & 4.72 \\
\hline 2 & $\begin{array}{l}\text { Concept of the } \\
\text { application }\end{array}$ & 31 & 15 & 3 & 1 & 0 & 226 & 50 & 4.52 \\
\hline & $\begin{array}{l}\text { Responding speed of } \\
\text { the applicatioc }\end{array}$ & 25 & 20 & 5 & 0 & 0 & 220 & 50 & 4.40 \\
\hline 4 & $\begin{array}{l}\text { User interactivity of } \\
\text { the system }\end{array}$ & 25 & 16 & 9 & 0 & 0 & 216 & 30 & 4,32 \\
\hline & $\begin{array}{l}\text { Accuracy level of the } \\
\text { results }\end{array}$ & 24 & 20 & 5 & 0 & 0 & 215 & 49 & 4,39 \\
\hline 6 & $\begin{array}{l}\text { Busisess moded for the } \\
\text { software }\end{array}$ & 29 & 11 & 8 & 1 & 0 & 215 & 49 & 439 \\
\hline & $\begin{array}{l}\text { Usefulness of the } \\
\text { spplication for } \\
\text { dereloping countries }\end{array}$ & 34 & 15 & 1 & 0 & 0 & 233 & 50 & 4.66 \\
\hline & & 207 & 106 & 32 & 3 & 0 & 1561 & 348 & 4.49 \\
\hline
\end{tabular}

Overall average rating of all evaluation aspects is about 4.49 which lies between 4 and 5 where 5 stands for "very good" and 4 stands for "good", addition to that above feedbacks, were saved other comments as well.

- Suggesting to adding some tutorial sessions for this web site.

- Suggesting to follow a method to confirm the people registered, are really university 7 +students

- Suggesting to develop a method for certifying the accuracy of answers.

- Giving an idea to upload video and audio clips to the system.

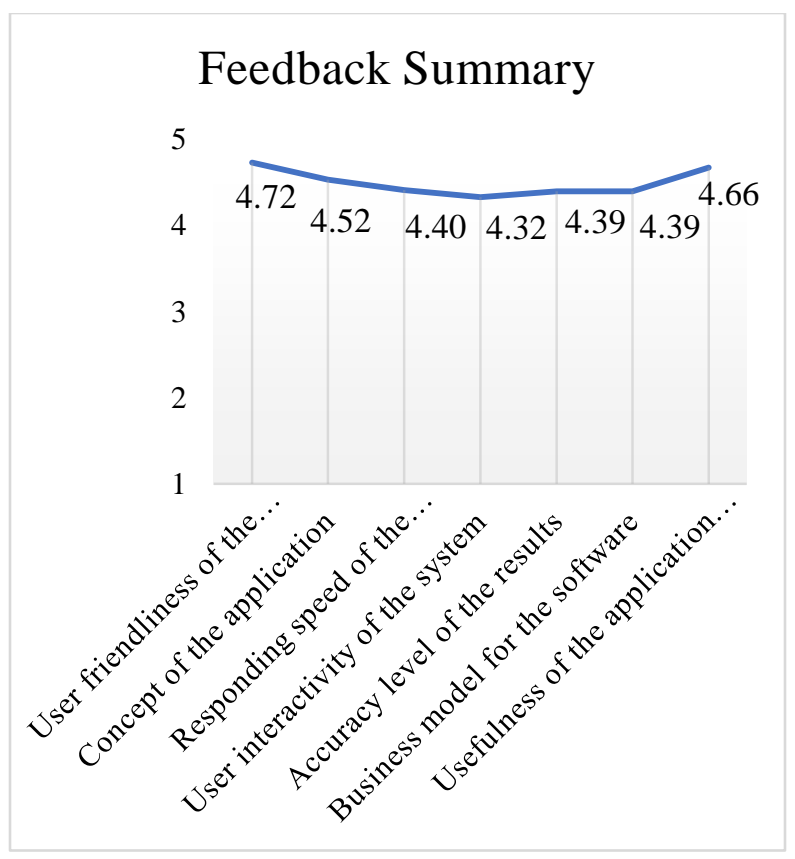

Figure 2: graphical user feedback summary

It can be seen from Figure 2 that the average rating for the first evaluation aspect: user friendliness of the application is about 4.7, which lies between 4 and 5 , where "4" stands for "Good" and "5" stands for "Very Good". Likewise, the average rating for the second evaluation aspect: concept of the application is about 4.5 it is also lying between 4 and 5 . Third evaluation aspect is responding speed of the application, which is about 4.4 average rate. User interactivity of the system is about 4.3 average rate, fifth evaluation aspect: accuracy level of the result and sixth evaluation aspect: business model for the software got 4.4 average rates. Average rating for seventh evaluation aspect is about 4.7 which also lies between 4 and 5.

\section{Limitation of our Proposed Solution}

When consider about our system boundaries, there are few limitations have been identified that we cannot be achieved. As following,

- Inability to access other online users except related university students.

- Users cannot view any questions or answers without log into system. 
Proc. of the Eighth Intl. Conf. on Advances in Computing, Electronics and Communication - ACEC 2019

Copyright $\odot$ Institute of Research Engineers and Doctors. All rights reserved.

ISBN: 978-1-63248-165-8 DOI : 10.15224/978-1-63248-165-8-02

\section{Further work}

Our prosed examination paper discussion platform can be further improved by adding feature like, Develop Android app. Because of Our system is web application, by using android technology it can be develop for mobile. By analyzing user feedbacks, we realized that suggestions which were given by users can be further improved such as develop a method for uploading audio and video clips in to the system and more effective method for certifying accuracy of answers.

\section{Conclusion}

At present there are so many students involve with online education to achieve their success. Through this paper we are intended to address university students' problem via internet. All these things are discussed through this paper. There are many learning and discussion platforms available in the world. In addition, they have many users that actively participate with them and get knowledge through them. However, there are no such kind of system special for university students to do examination paper discussions. Therefore, we decided to develop a system for university students to collaboratively discuss past papers. So, we developed examination paper discussion platform by using technologies and design methods. System development is done by sequentially, achieving objectives we proposed.Then proposed system was evaluate qualitatively by getting feedbacks from undergraduates students through the questionnaire and module testing was done for evaluating the system technically. There are some limitations we could not be achieved such as Inability to access other online users except related university students and Users cannot view any questions or answers without log into system. Our system mainly based on web application and we explain further developments that we can do.

\section{Acknowledgement}

We would like to express our special thanks of gratitude to Mr. Thishantha Thilakarathne, Virtusa Polaris Pvt. Ltd and Mrs. K.A.Dilini T. Kulawansa who constantly motivating and guiding us.

\section{Reference}

[1] Zhe Liu and Bernard J. Jansen, Analysis of Question and Answering Behavior in Question Routing Services, Zhe Liu, College of Information Sciences and Technology, The Pennsylvania State University, University Park, Pennsylvania 16802, Bernard J. Jansen, Social Computing Group, Qatar Computing Research Institute, HBKU, Doha, Qatar https://faculty.ist.psu.edu/jjansen/academic/jansen_qanda_wenwo. pdf

[2] L Luo, F Wang, MX Zhou, Y Pan, H Chen (2014), Who have got answers? Growing the pool of answerers in a smart enterprise social QA system http://dl.acm.org/citation.cfm?id=2557531

[3] Zainab Zolaktaf, Fatemeh Riahi, Mahdi Shafiei, Evangelos Milios, 2011. Modeling Community Question Answering archives. In Workshop on Computational Social Science and the Wisdom of Crowds, Neural Information Processing Systems, December 17, 2011, Sierra Nevada, Spain. https://web.cs.dal.ca/ eem/crWeb/bib/2011-Zolaktaf-NIPS.bib https://web.cs.dal.ca/ eem/cvWeb/pubs/2011-Zolaktaf-NIPS.pdf [4] Zhe Liu and Bernard J. Jansen, Analysis of Question and Answering Behavior in Question Routing Services, Zhe Liu, College of Information Sciences and Technology, The Pennsylvania State University, University Park, Pennsylvania 16802, Bernard J. Jansen, Social Computing Group, Qatar Computing Research Institute, HBKU, Doha, Qatar https://faculty.ist.psu.edu/jjansen/academic/jansen_qanda_wenwo. pdf

[5] L Luo, F Wang, MX Zhou, Y Pan, H Chen (2014), Who have got answers? Growing the pool of answerers in a smart enterprise social $Q A$ system http://dl.acm.org/citation.cfm?id=2557531

[6] Zainab Zolaktaf, Fatemeh Riahi, Mahdi Shafiei, Evangelos Milios, 2011. Modeling Community Question Answering archives. In Workshop on Computational Social Science and the Wisdom of Crowds, Neural Information Processing Systems, December 17, 2011, Sierra Nevada, Spain. https://web.cs.dal.ca/ eem/cvWeb/bib/2011-Zolaktaf-NIPS.bib https://web.cs.dal.ca/ eem/cvWeb/pubs/2011-Zolaktaf-NIPS.pdf [7] Zolt 'an Gy"ongyi, Stanford University, Georgia Koutrika, Stanford University, Jan Pedersen, Yahoo! Inc., CA 94089, USA, Hector GarciaMolina, Stanford University Questioning Yahoo! Answers http://ilpubs.stanford.edu/819/1/2007-35.pdf

[8] https://stackoverflow.com/tour

[9] https://en.wikipedia.org/wiki/Quora

[10]https://en.wikipedia.org/wiki/Answers.com

[11] Zhe Liu and Bernard J. Jansen, Analysis of Question and Answering Behavior in Question Routing Services, Zhe Liu, College of Information Sciences and Technology, The Pennsylvania State University, University Park, Pennsylvania 16802, Bernard J. Jansen, Social Computing Group, Qatar Computing Research Institute, HBKU, Doha, Qatar https://faculty.ist.psu.edu/jjansen/academic/jansen_qanda_wenwo. pdf

[12] L Luo, F Wang, MX Zhou, Y Pan, H Chen (2014), Who have got answers? Growing the pool of answerers in a smart enterprise social QA system http://dl.acm.org/citation.cfm?id=2557531

[13] Zainab Zolaktaf, Fatemeh Riahi, Mahdi Shafiei, Evangelos Milios, 2011. Modeling Community Question Answering archives. In Workshop on Computational Social Science and the Wisdom of Crowds, Neural Information Processing Systems, December 17, 2011, Sierra Nevada, Spain. https://web.cs.dal.ca/ eem/cvWeb/bib/2011-Zolaktaf-NIPS.bib https://web.cs.dal.ca/ eem/cvWeb/pubs/2011-Zolaktaf-NIPS.pdf

[14] Zolt 'an Gy“ongyi, Stanford University, Georgia Koutrika, Stanford University, Jan Pedersen, Yahoo! Inc., CA 
Proc. of the Eighth Intl. Conf. on Advances in Computing, Electronics and Communication - ACEC 2019

Copyright $\odot$ Institute of Research Engineers and Doctors. All rights reserved.

ISBN: 978-1-63248-165-8 DOI : 10.15224/978-1-63248-165-8-02

94089, USA, Hector GarciaMolina, Stanford University Questioning Yahoo! Answers http://ilpubs.stanford.edu/819/1/2007-35.pdf

[15]https://stackoverflow.com/tour

[16]https://en.wikipedia.org/wiki/Quora

[17]https://en.wikipedia.org/wiki/Answers.com

[18]https://en.wikipedia.org/wiki/Apache_HTTP_Server

[19] https://en.wikipedia.org/wiki/PHP

[20] https://www.tutorialspoint.com/mysql/mysql tutorial.pdf

[21]https://en.wikipedia.org/wiki/HTML

[22] http://www.tutorialspoint.com/css/css_tutorial.pdf

[23]www.tutorialspoint.com/javascript/javascript_tutorial.pdf

[24]https://www.tutorialspoint.com/bootstrap/bootstrap_tutorial. pdf

[25]www.the-software-experts.com/e dta-sw-design-

module.php [26]www.smartdraw.com/flowchart/flowcharttips.htm [27]www.youtube.com/watch?v=y9Bhii0VHkA

[28]www.fao.org/docrep/w3241e/w3241e05.htm

[29]www.computer.org/csdl/trans/lt/2010/02/index.html

[30]https://wiki.ecdc.europa.eu/fem/w/wiki/ten-steps-to-designa-questionnaire 